\title{
Topographical and Tribological Characteristics of Asian Human Hair Cuticles
}

\author{
Chia-Ling Chang, ${ }^{1,2}$ Tsung-Han Ho, ${ }^{1}$ and Te-Hua Fang ${ }^{3}$ \\ ${ }^{1}$ Department of Chemical and Materials Engineering, National Kaohsiung University of Applied Sciences, Kaohsiung 807, Taiwan \\ ${ }^{2}$ Department of Beauty and Health Care, Min-Hwei Junior College of Health Care Management, Tainan 736, Taiwan \\ ${ }^{3}$ Department of Mechanical Engineering, National Kaohsiung University of Applied Sciences, Kaohsiung 807, Taiwan
}

Correspondence should be addressed to Te-Hua Fang; fang@cc.kuas.edu.tw

Received 23 September 2014; Accepted 26 December 2014

Academic Editor: Mo Li

Copyright (c) 2015 Chia-Ling Chang et al. This is an open access article distributed under the Creative Commons Attribution License, which permits unrestricted use, distribution, and reproduction in any medium, provided the original work is properly cited.

\begin{abstract}
The topography and frictional force of Asian black male and female hair cuticles at different locations are determined using atomic force microscopy (AFM) and friction force microscopy (FFM). The frictional values, mapped for comparison with surface morphology, corresponded qualitatively with the structures' plane surface characteristics. The results indicate that the hair surface was damaged and modified at different temperatures and heating times. The height of the female hair at a blowing temperature of $60^{\circ} \mathrm{C}$ after a duration of $2 \mathrm{~min}$ between the cuticle edge and cuticle surface was approximately $440-556 \mathrm{~nm}$. The adhesion phenomenon occurs on the hair surface and interface. The cuticles do not vary after the heating; however, the hair damage sustained increases with serious deterioration.
\end{abstract}

\section{Introduction}

Human hair is a natural fiber with an exceedingly complex structure [1]. The human hair surface comprises three layers, an outer cuticle layer, a middle cortex layer, and an inner medulla layer. The cuticle layer comprises a cuticle and a cell membrane complex with intercalated flattened cells. The medullar layer of the hair shaft consists mainly of the cortical layer and the epidermis; the hair root contains the hair follicles, hair bulb, dermal papilla, and hair matrix cells [2]. The cell membrane complex comprises a hydrophilic layer (delta-layer) and two hydrophobic layers (beta-layers) [3].

Recently, the surface and structure of human hair have been studied using various techniques, such as scanning electron microscopy (SEM) [4] and transmission electron microscopy (TEM) [5]. Atomic force microscopy (AFM) has now proven to be a valuable experimental tool, particularly in nanotribology, materials science, and the surface science. Frictional force microscopy (FFM) is a useful tool for providing nondestructive measurement of hair fiber and cuticular surfaces [6]. Bhushan [7] studied nanoscale characterization of the cellular structure, mechanical properties, and morphological, frictional, and adhesive properties of hair. Seshadri and Bhushan [8] studied the tensile deformation properties of Caucasian virgin damaged hair samples. Sadaie et al. [9] employed frictional force microscopy with a selfassembled monolayer (SAM) modified probe to understand the frictional properties of the hair surface.

This study investigates the nanomechanical properties of human hair using AFM and FFM. The topography and images of Asian female and male hair cuticle surfaces at different locations are presented. The blowing temperature on the surface morphology, microstructures, and frictional force of female hair cuticles are also explored.

\section{Methodology}

Asian black virgin hair samples were used without any chemical treatment. The samples were washed with distilled water before use to reduce the number of deposits. The cleanest hair sections located near the roots were selected. The hair sample was collected from the scalp from an approximately $1 \mathrm{~mm}$ uniform test site to the right of the hair; hair detection was performed at room temperature. 


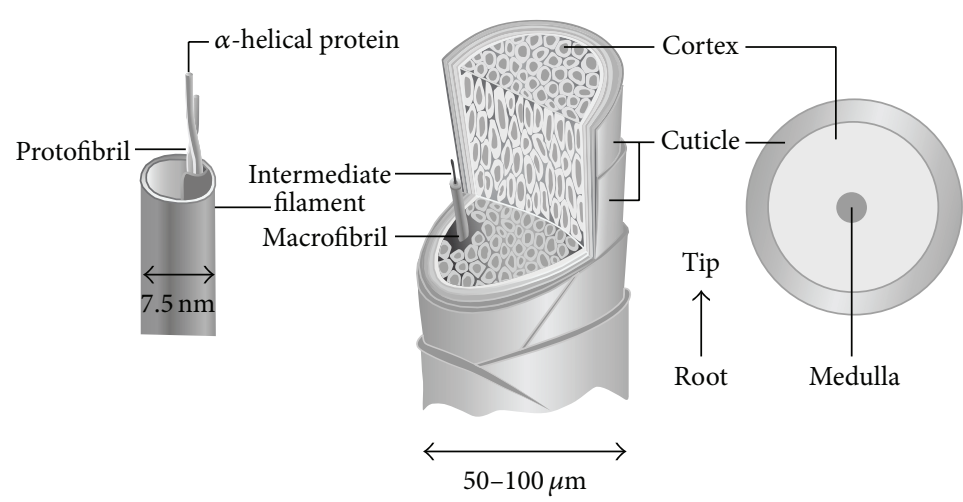

(a)

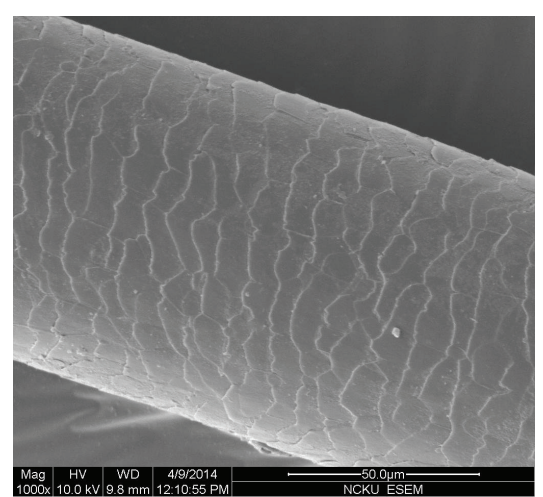

(b)

FIGURE 1: (a) Schematic of hair fiber microstructure and (b) scanning electronic microscope image of hair cuticle surface.

Using the original contact atomic force microscope, the distribution of the frictional force was measured using a Bruker commercial AFM system in contact mode with a silicon tip. The AFM was equipped with a top-view optical microscope. The scanning rate was approximately $1.5 \mathrm{~Hz}$, and the scan range was approximately $10 \mu \mathrm{m}$. The AFM was operated in a laboratory controlled to a temperature of approximately $22^{\circ} \mathrm{C}$ and a relative humidity of approximately $50 \%$.

The surface roughness of the hair surfaces can be obtained by determining the root mean square average (RMS) roughness in vertical direction $[10,11]$. The RMS is defined as follows:

$$
\mathrm{RMS}=\sqrt{\frac{1}{n} \sum_{i=1}^{n} z_{i}^{2}}
$$

where $z_{i}$ is the surface profile and $n$ is the total number of pixels in the profile dimension.

\section{Results and Discussion}

Figure 1 shows the hair fiber structure. In Figure 1(a), the hair fiber is divided into three layers: the epidermis, cortex, and medulla layer. In the first layer, the main function of the epidermis is to protect the hair inside and to resist external stimuli. In the second layer, the cortical layer is mainly concerned with the physical and chemical properties but also determines the main layer of the hair color. The third layer, the medullary layer, is mainly connected to the scalp hair follicles to maintain the growth of the most important places to maintain adequate nutrition of the medullary layer such that the hair will be healthy. Figure 1(b) presents a scanning electronic microscope (SEM) image of the human hair structure.

Figure 2 presents a schematic view of an atomic force microscope force-distance curve. At point a, by the side remote from the probe surface, because there is no force acting between the object and the probe by the side, the side

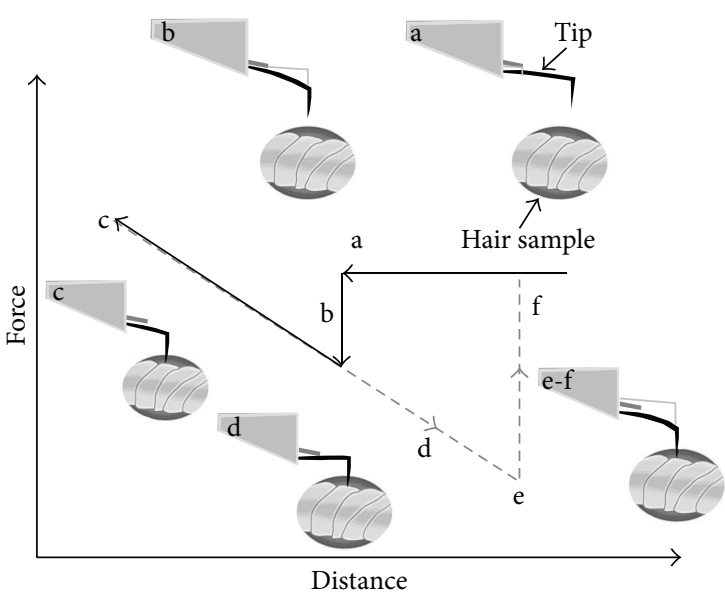

FIGURE 2: Force and displacementat of the probe tip-sample separations.

surface is not deformed when the probe approaches the surface side of point $b$. Due to the gravitational pull between the surface and the probe, the tip is bent to the side of the object; the gravitational force is adsorbed on the surface layer of the probe surface [12].

Figure 3 presents topography AFM images of Asian male and female cuticle surfaces at different locations. Figures 3(a1), 3(a2), 3(a3), and 3(a4) correspond to the eyebrow, leg, facial whiskers, and hair surfaces of Asian males, respectively. The AFM images of various hair location surfaces along with section plots are presented. The results reveal that all the cuticle cells of the male leg, facial whiskers, and hair surfaces are nearly parallel to the underlying cuticle cells. The eyebrow cuticle has a shape cuticle structure around the edge. All the cuticle cells exhibit similar angles to the hair axis and form a tile-like hair surface structure. The visible cuticle thickness of the eyebrow, leg, facial whiskers, and hair surfaces of Asian males are approximately $0.3-0.6,0.4-$ $0.8,0.3-1.5$, and $1.0-2.0 \mu \mathrm{m}$, respectively. The visible cuticle 


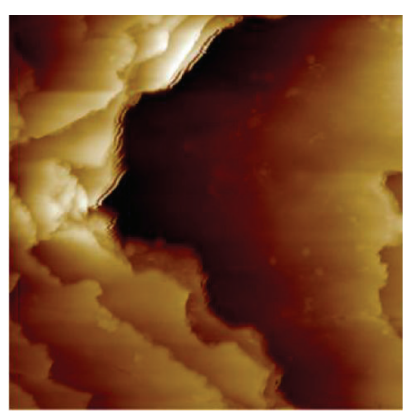

(a1) Eyebrow

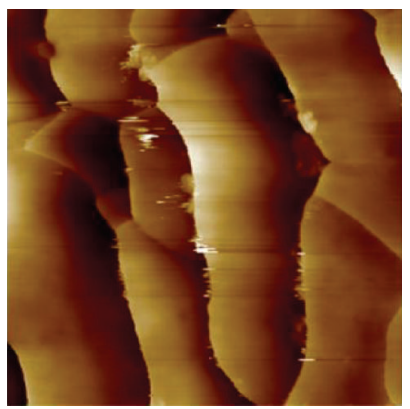

(b1) Eyebrow

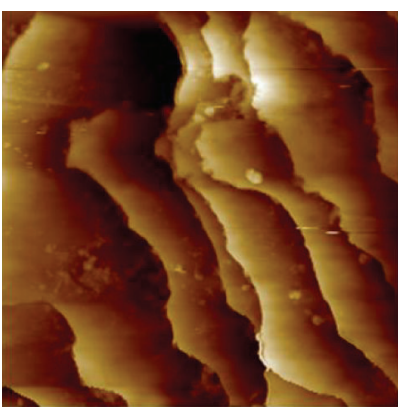

(a2) Leg

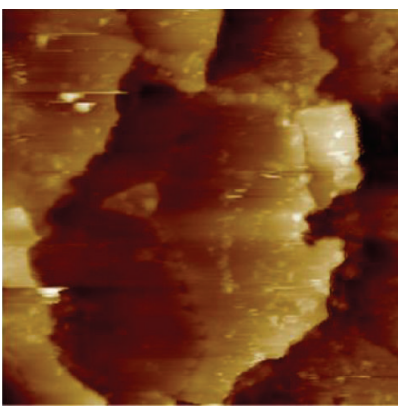

(b2) Arm

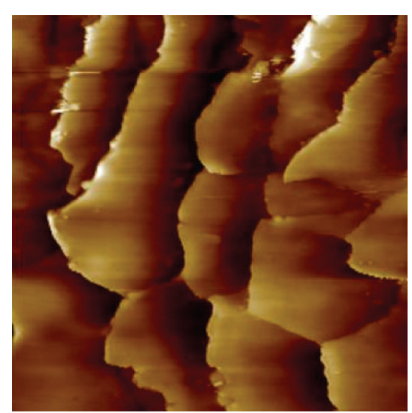

(a3) Whiskers facial hair

(a)

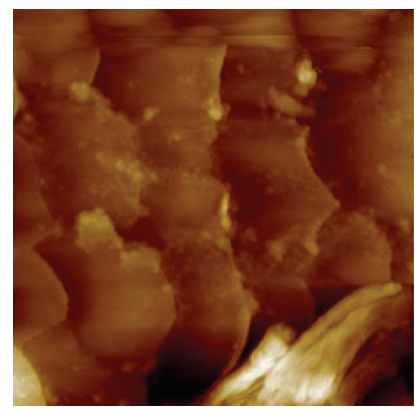

(b3) Armpit

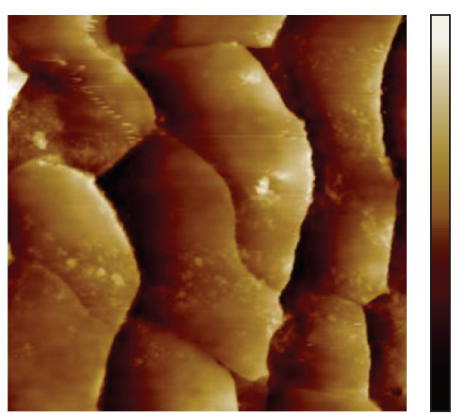

(a4) Hair

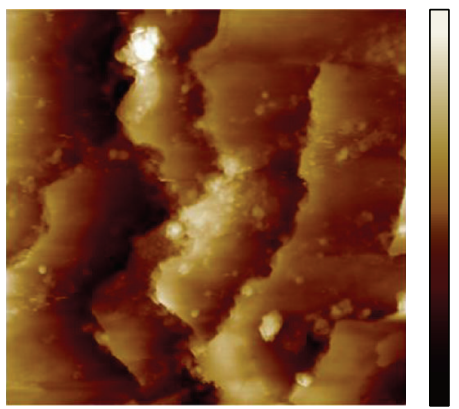

(b4) Hair

(b)

Figure 3: AFM images of (a) the male and (b) female cuticle surface at different locations.

length of the eyebrow, leg, facial whiskers, and hair surfaces of Asian males is approximately 4-10, 5-12, 5-9, and 5-10 $\mu \mathrm{m}$, respectively.

Figures 3(b1), 3(b2), 3(b3), and 3(b4) show AFM images corresponding to the eyebrow, arm, armpit, and hair surfaces of Asian females, respectively. The visible cuticle thickness of the eyebrow, arm, armpit, and hair surfaces of females is approximately $0.2-0.5,0.1-0.5,0.3-1.0$, and $0.5-1.0 \mu \mathrm{m}$, respectively. The surface roughness RMS of the male and female cuticle surfaces was $9-23 \mathrm{~nm}$ and $8-34 \mathrm{~nm}$, respectively.

The visible cuticle length of the eyebrow, arm, armpit, and hair surfaces of the female is approximately 5-10, 3-7, 5-11, and 5-8 $\mu \mathrm{m}$, respectively. The hair cuticle edge thickness of the female is less than that of the male at different locations. LaTorre and Bhushan [4] reported similar results of the cuticle thickness and length of approximately $0.3-0.5$ and 5$10 \mu \mathrm{m}$, respectively.

Figure 4 presents FFM images of Asian male and female cuticle surfaces at different locations for an applied load of $2 \mathrm{~V}$. Here, a $1 \mathrm{~V}$ change corresponds to a change in the apparent applied load of $10 \mathrm{nN}$. Although the topographic FFM image was not greatly changed by the applied load, the FFM image reveals that the surface was disturbed by probe scanning. The image shows that the frictional force surfaces of the hair cuticle were related to the surface topography. The edges of the cuticular substructures of the male and female hairs were shaded. The frictional force value of the female is less than that of the male.
Figures 5(a)-5(d) present AFM images of the female cuticle surface at various temperatures for $2,4,6$, and $10 \mathrm{~min}$, respectively. The surface temperatures for blowing time durations of $2,4,6$, and 10 min were approximately 60 , 65,70 , and $75^{\circ} \mathrm{C}$ on the hair cuticle structures, respectively. The RMS surface roughness of the female cuticle surface at temperatures of $60^{\circ} \mathrm{C}-75^{\circ} \mathrm{C}$ was $8-22 \mathrm{~nm}$.

Figures $6(\mathrm{a})-6(\mathrm{~d})$ present FFM images of the frictional force distribution of the female cuticle surface at blowing temperatures of time durations of $2,4,6$, and $10 \mathrm{~min}$, respectively. Damage of the cuticle layers occurred, and the disordered structure and edges of several cuticles were corrugated after blowing temperatures of time durations of $4 \mathrm{~min}$. The reason is due to the hair being delaminated after blow drying.

\section{Conclusions}

The properties of the human hair cuticle of Asian females and males at various locations were investigated using atomic force microscopy (AFM) and frictional force microscopy (FFM). From the microstructural perspective, the cuticles in human hair are approximately 10-scale thickness. The interfaces between the cuticle edge and cuticle layers increase the frictional force and interaction on the cuticle surface.

\section{Conflict of Interests}

The authors declare that there is no conflict of interests regarding the publication of this paper. 


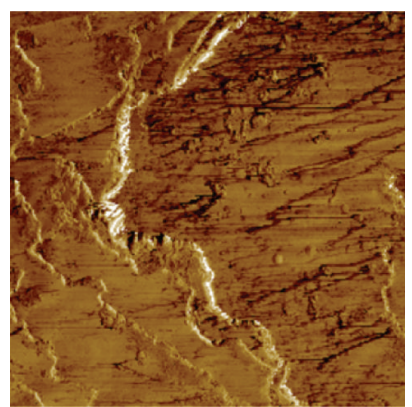

(a1) Eyebrow

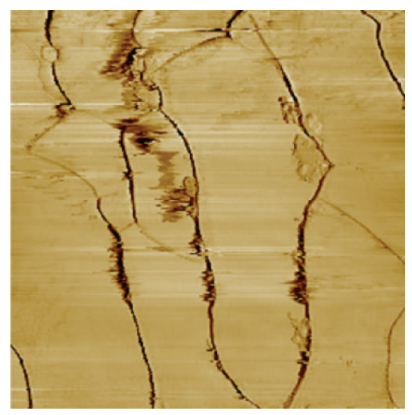

(b1) Eyebrow

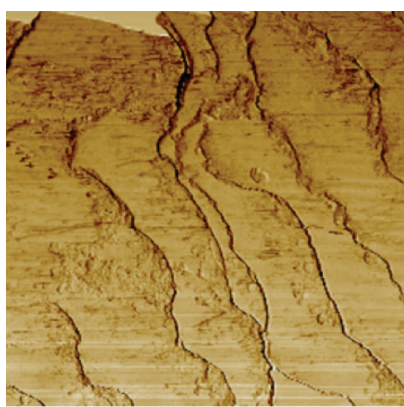

(a2) Leg

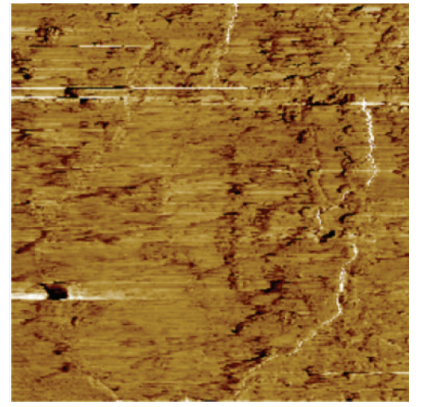

(b2) Arm

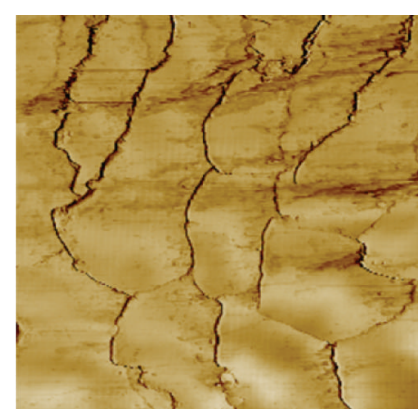

(a3) Whiskers facial hair

(a)

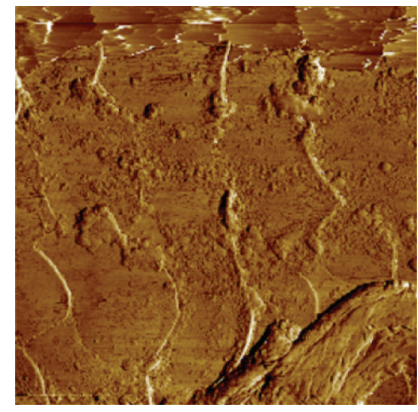

(b3) Armpit

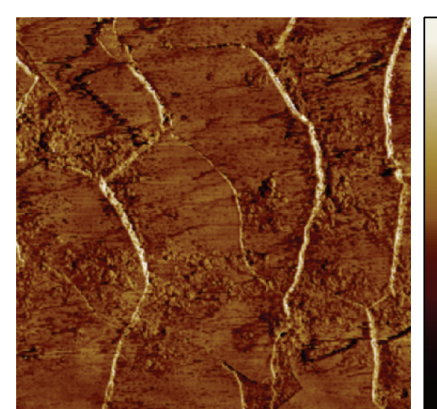

(a4) Hair

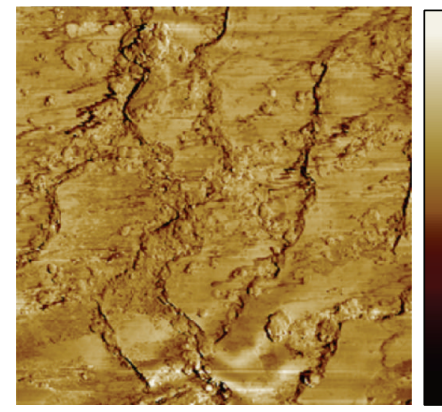

(b4) Hair

(b)

FIgURE 4: FFM images of (a) the male and (b) female cuticle surface at different locations.

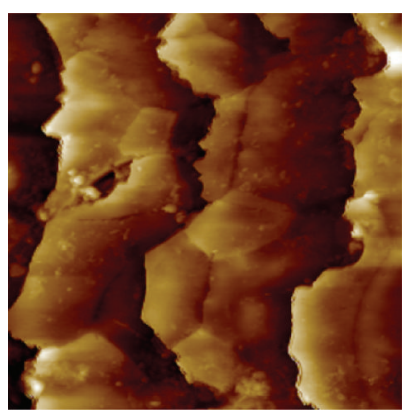

(a)

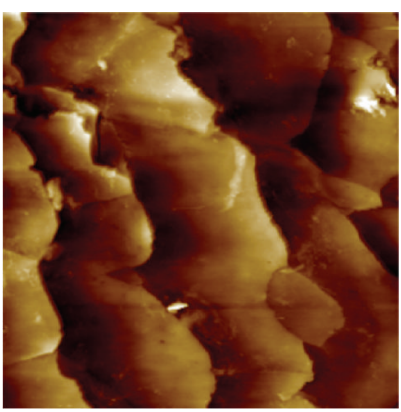

(b)

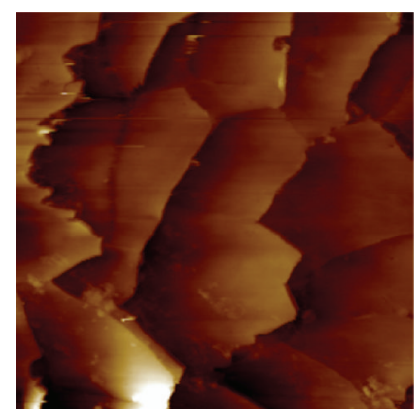

(c)

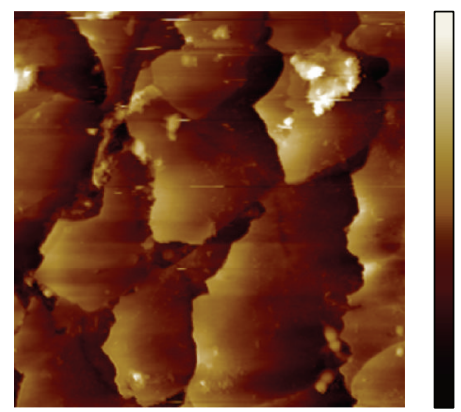

(d)

Figure 5: AFM images of (a) the female cuticle surface at different temperatures of (a) $2 \mathrm{~min}$, (b) $4 \mathrm{~min}$, (c) 6 min, and (d) $10 \mathrm{~min}$.

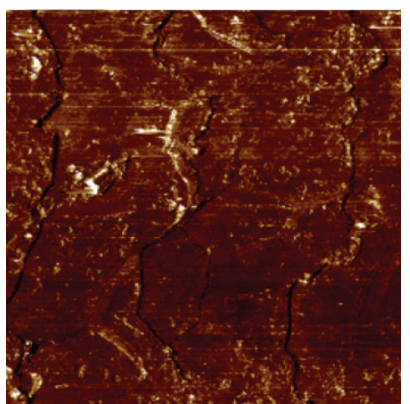

(a)

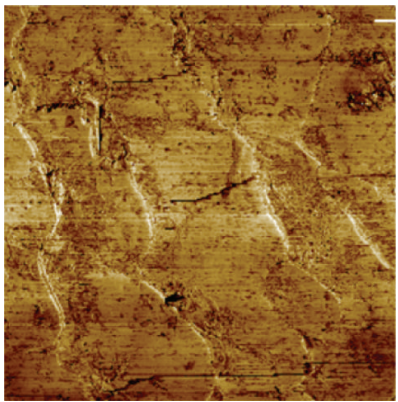

(b)

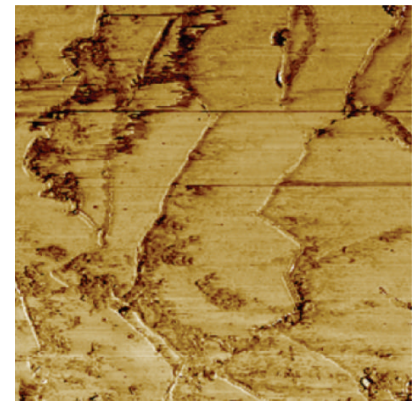

(c)

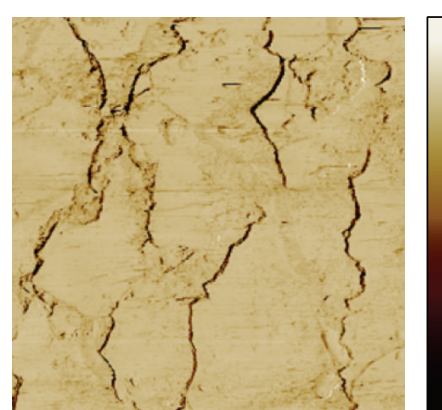

(d)

FiguRE 6: FFM images of (a) the female cuticle surface at different temperatures of (a) 2 min, (b) 4 min, (c) 6 min, and (d) 10 min. 


\section{Acknowledgments}

This work was partially supported by the Ministry of Science and Technology of Taiwan under NSC 100-2626E151-003MY3. The authors would like to thank Enago (http://www.enago.tw) for the English language review.

\section{References}

[1] B. Bhushan and N. Chen, "AFM studies of environmental effects on nanomechanical properties and cellular structure of human hair," Ultramicroscopy, vol. 106, no. 8-9, pp. 755-764, 2006.

[2] H. Tohmyoh, M. Ishihara, M. A. Salam Akanda, S. Yamaki, T. Watanabe, and T. Iwabuchi, "Accurate determination of the structural elasticity of human hair by a small-scale bending test," Journal of Biomechanics, vol. 44, no. 16, pp. 2833-2837, 2011.

[3] L. N. Jones, "The hair fiber surface," in Forslind in Skin, Hair and Nails: Structure and Function, pp. 273-317, Marcel Dekker, New York, NY, USA, 2004.

[4] C. LaTorre and B. Bhushan, "Nanotribological characterization of human hair and skin using atomic force microscopy," Ultramicroscopy, vol. 105, no. 1-4, pp. 155-175, 2005.

[5] J. A. Swift, V. Dupres, and T. Cames, "Fine details on the surface of human hair," International Journal of Cosmetic Science, vol. 13, pp. 143-159, 1991.

[6] V. Dupres, T. Camesano, D. Langevin, A. Checco, and P. Guenoun, "Atomic force microscopy imaging of hair: correlations between surface potential and wetting at the nanometer scale," Journal of Colloid and Interface Science, vol. 269, no. 2, pp. 329335, 2004

[7] B. Bhushan, "Nanoscale characterization of human hair and hair conditioners," Progress in Materials Science, vol. 53, no. 4, pp. 585-710, 2008.

[8] I. P. Seshadri and B. Bhushan, "In situ tensile deformation characterization of human hair with atomic force microscopy," Acta Materialia, vol. 56, no. 4, pp. 774-781, 2008.

[9] M. Sadaie, N. Nishikawa, S. Ohnishi, K. Tamada, K. Yase, and M. Hara, "Studies of human hair by friction force microscopy with the hair-model-probe," Colloids and Surfaces B: Biointerfaces, vol. 51, no. 2, pp. 120-129, 2006.

[10] Y.-R. Jeng, P.-C. Tsai, and T.-H. Fang, "Nanomeasurement and fractal analysis of PZT ferroelectric thin films by atomic force microscopy," Microelectronic Engineering, vol. 65, no. 4, pp. 406$415,2003$.

[11] T.-H. Fang, S.-R. Jian, and D.-S. Chuu, "Nanotribology and fractal analysis of $\mathrm{ZnO}$ thin films using scanning probe microscopy," Journal of Physics D: Applied Physics, vol. 36, no. 7, pp. 878-883, 2003.

[12] T.-H. Fang, S.-H. Kang, Z.-H. Hong, and C.-D. Wu, "Elasticity and nanomechanical response of Aspergillus niger spores using atomic force microscopy," Micron, vol. 43, no. 2-3, pp. 407-411, 2012. 


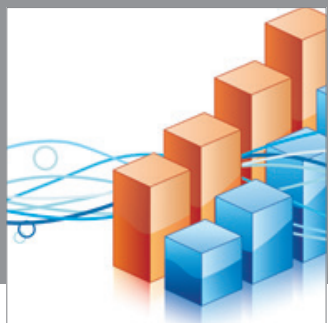

Advances in

Operations Research

mansans

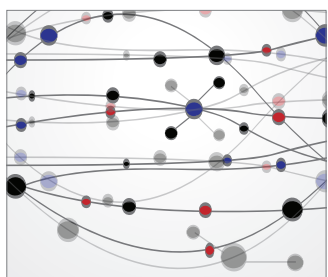

The Scientific World Journal
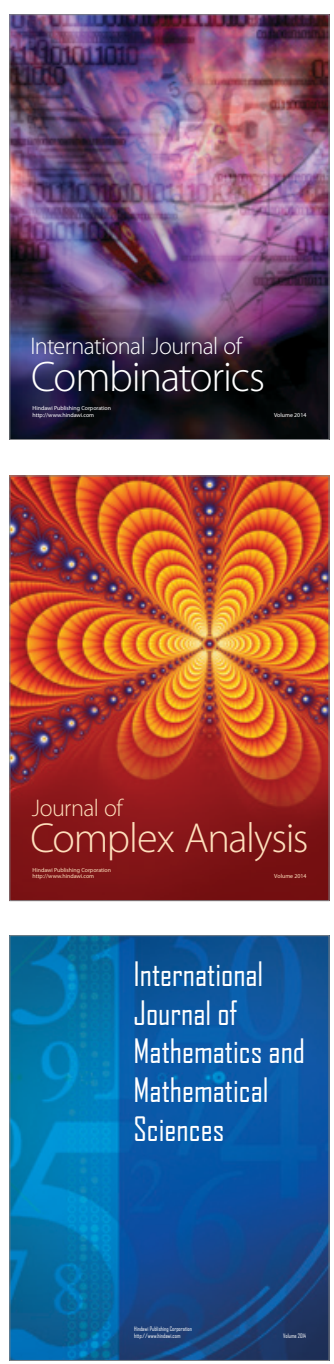
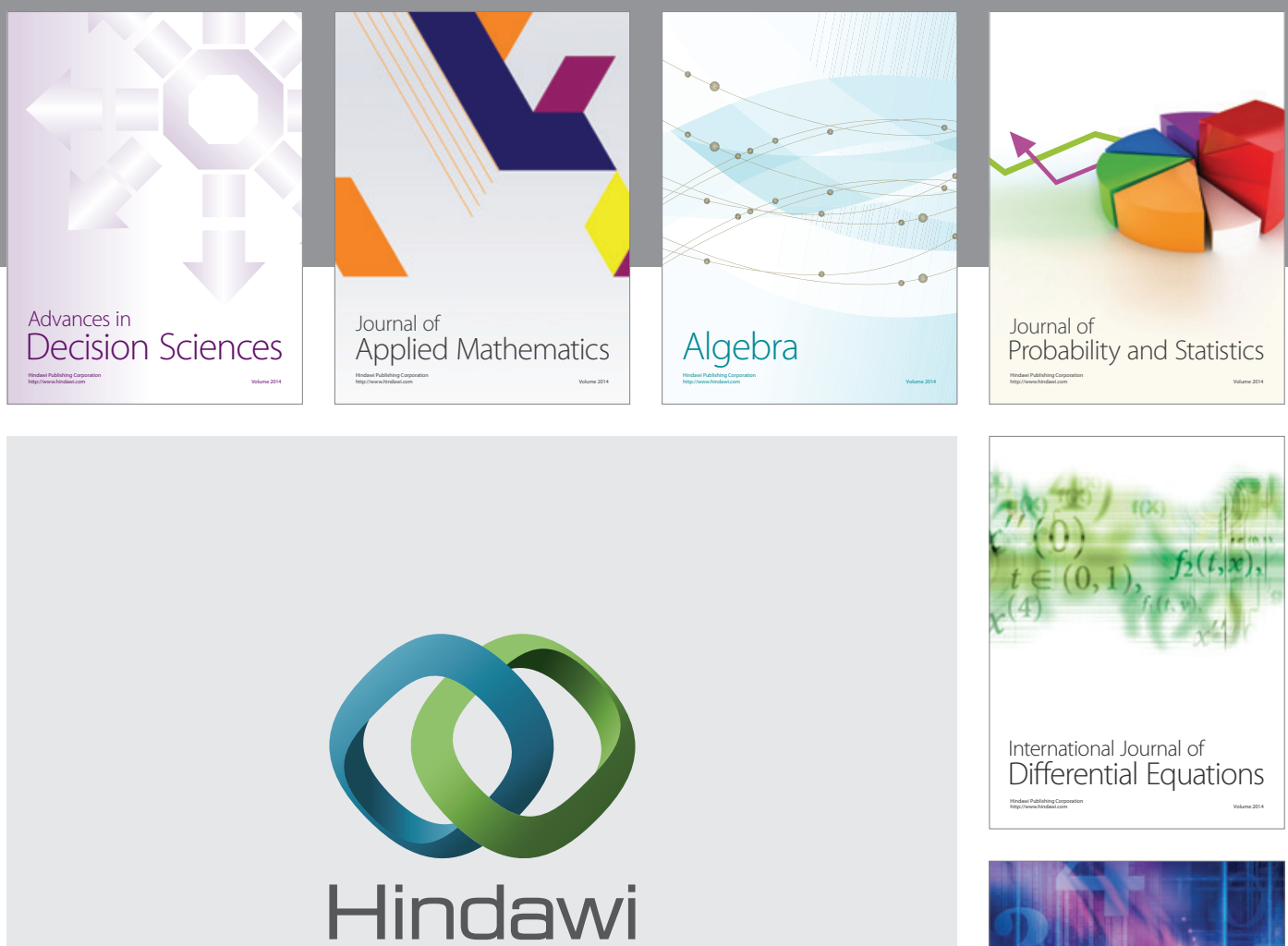

Submit your manuscripts at http://www.hindawi.com
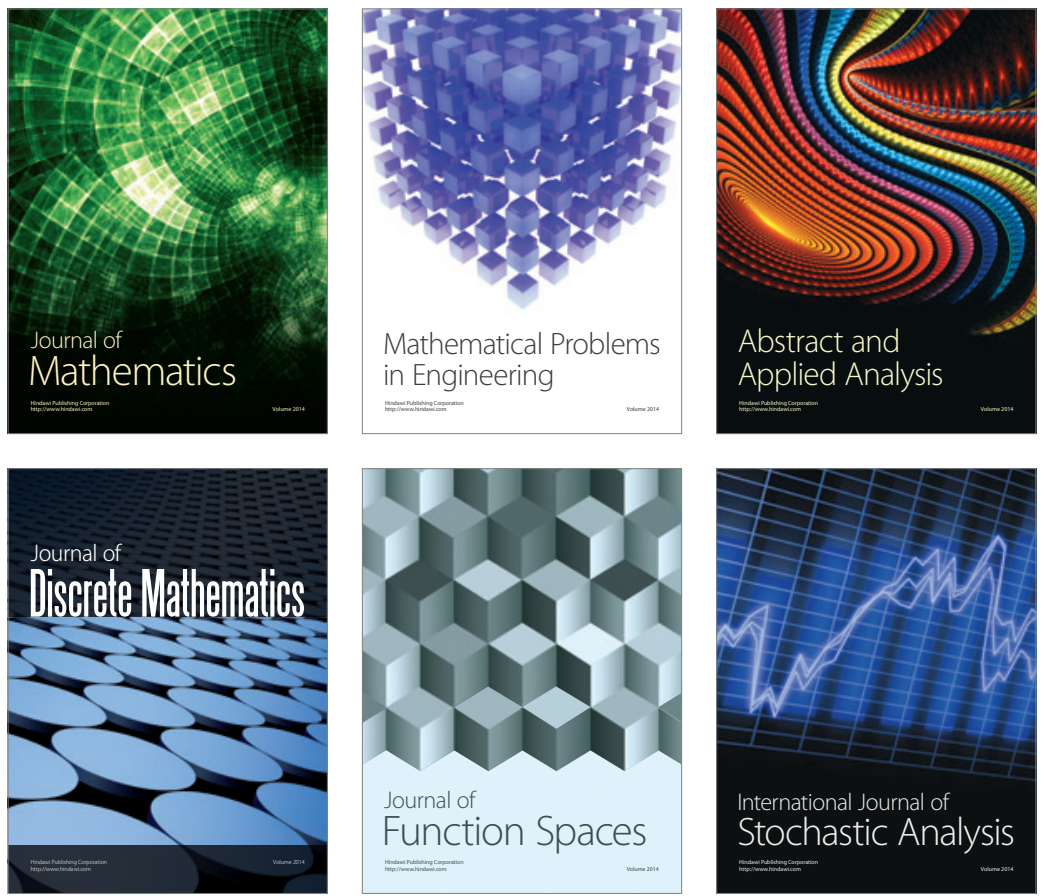

Journal of

Function Spaces

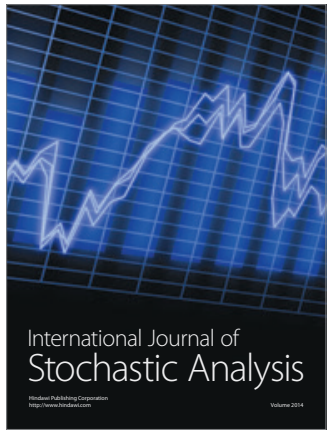

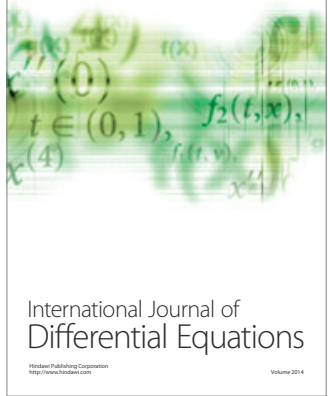
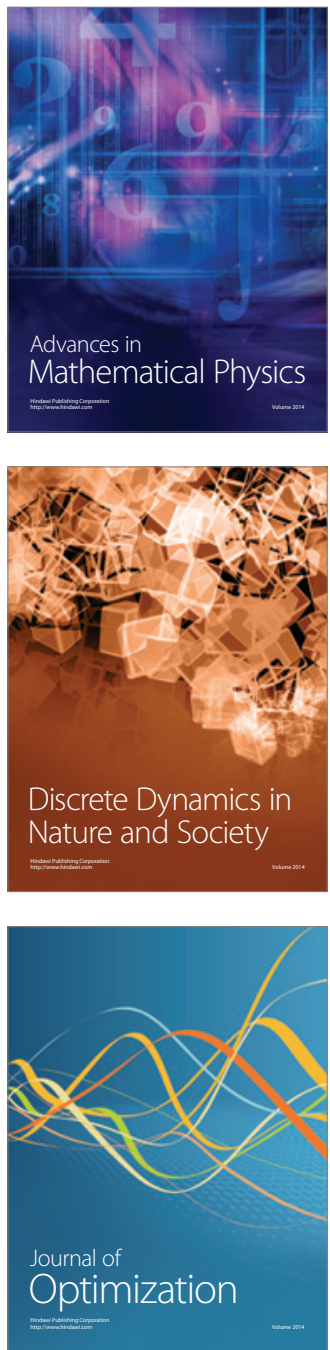